\title{
UAV Mapping of an Archaeological Site Using RGB and NIR High-Resolution Data ${ }^{\dagger}$
}

\author{
Lucie Koucká $1{ }^{* *}$, Veronika Kopačková ${ }^{1}$, Kateřina Fárová ${ }^{1}$ and Martin Gojda ${ }^{2}$ \\ 1 Remote Sensing Department, Czech Geological Survey, Klarov 3, Prague 118 21, Czech Republic; \\ veronika.kopackova@seznam.cz (V.K.); katerina.farova@geology.cz (K.F.) \\ 2 Institute of Archaeology of the Czech Academy of Sciences, Letenska 4, Prague 118 01, Czech Republic; \\ martin.gojda@seznam.cz \\ * Correspondence: lucie.koucka@geology.cz; Tel.: +420-257-089-438 \\ + Presented at the 2nd International Electronic Conference on Remote Sensing, 22 March-5 April 2018; \\ Available online: https://sciforum.net/conference/ecrs-2.
}

Published: 22 March 2018

\begin{abstract}
During the last decade, remote sensing methods have developed significantly. The technological progress in development of new sensors and techniques opened up a large scope of new applications including near-field data collecting using Unmanned Aerial Vehicles (UAVs). State-of-the-art UAV technologies provide advantages including cost-effectiveness and temporal flexibility. For our case study, we acquired the high-resolution UAV data over the archaeological site near Černouček, the Czech Republic. This site was discovered at the beginning of 1990s as a result of low altitude aerial reconnaissance carried out by the Institute of Archaeology, Czech Academy of Sciences. Two ditched enclosures were identified due to vegetation marks in late spring and early summer, as higher moisture and presence of some chemical constituents in the secondary infill of the ditches give better conditions for plants above them. In 2017, new UAV data (Red, Green and Blue: RGB and Red and Near-infrared data: Red + NIR) were acquired over the Černouček site in June to find out whether there are some other objects hidden under ground. Using the RGB data digital elevation models were derived while the Red + NIR data were used to compute vegetation indices (VI), further spatial filtering allowing enhancing the local anomalies in the VI values was employed. As a result, several small objects were detected and suggested for the further investigations.
\end{abstract}

Keywords: unmanned aerial vehicle; archaeology; near-infrared; digital elevation model; remote sensing

\section{Introduction}

Remote sensing in archaeology includes the application of techniques which allow the detection and documentation of both structures (features) completely buried under the earth surface, and preserved on the ground in the form of ruined monuments (so-called earthworks). Between the 1920s and 1980/90 a visual reconnaissance was practiced using small aircrafts flying at a low altitude by trained specialists: aerial archaeologists. Since at least the beginning of this century, when high (spatial and spectral) resolution space-borne and air-borne imagery became available for applications in non-military research projects, the potential of multispectral (optical) data has been tested in archaeology repeatedly through a variety of techniques, such as vegetation indices, principal component analysis, orthogonal equations, etc. [1-7]. In the context of recent technological developments, when UAVs have provided a low-cost and effective way of acquiring data and started to be used for many purposes [8,9], new miniature multispectral cameras have been developed offering high spatial resolution data for other analyses $[10,11]$. New possibilities for archaeological 
survey, mapping and 3D modeling in site-based and small landscape transects scales have appeared $[12,13]$. Such joint applications have recently started to be tested in the practice of Czech archaeology.

This paper presents the first results of a project (first of its kind in Czech archaeology) aimed at the detection, via RGB and Red + NIR data acquired by UAV-based small scanners, of prehistoric funerary features which have not been evidenced by previous aerial observation.

\section{Experiments}

\subsection{Study Area}

The archaeological site at Černouček is situated $40 \mathrm{~km}$ north of Prague on the large plateau raised above the river Labe basin. This area, situated around the dominant solitary hill of Říp, belongs among the most extensively settled regions of prehistoric Bohemia. In the last two decades the Říp region has become one of the main areas in Bohemia where modern procedures of archaeological prospection have been applied [14]. The potential of preferably non-invasive methods, and their combination with traditional approaches have been tested here in large scale. Several tens of archaeological sites dated to the Neolithic, Bronze- and Iron Ages, Roman period and early Middle Ages (5.500 BC-1.100 AD) have been evidenced during the last 25 years as a result of systematic aerial reconnaissance over Czech (Bohemian) lowlands.

An increasing number of prehistoric sites discovered through aerial survey over the Říp region are evidenced by a wide variety of archaeological components. Palimpsests created by overlapping features (houses, pits, enclosures), visible seasonally (May-July) from above due to the differences in size and colour of vegetation growing above buried (sunken) archaeological features, indicate the existence of several settlement areas and burial sites spread around the Říp.

Apart from prehistoric rural settlements (villages) a few funerary sites have been discovered in that region through aerial prospection. They usually include 1-5 burials of which each consists of a pit grave surrounded by a circular or rectangular ditched enclosure $[15,16]$.

The burial site near Černouček consists of four ditched enclosures - two of rectangular and two of circular ground-plan (Figure 1), with grave pits placed in their centre-were detected and airphotographically (in panchro) documented not only once but several times between the 1990s and 2010. All of these features were identified due to crop/vegetation marks in late spring, early summer. Principally, higher moisture and presence of some chemical constituents (such as phosphorus) present in the secondary infill of the ditches and pits conform better conditions for plants growing above them. As a consequence, changes in colour and height of such plants towards the end of the vegetation period indicate the presence of buried features [17].

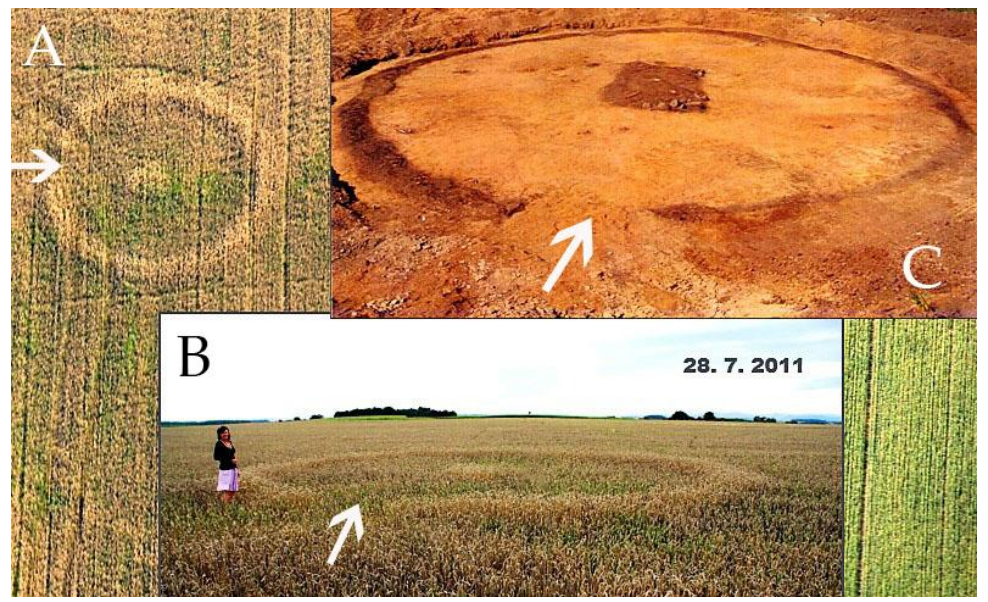

Figure 1. The circular ditched enclosure near Černouček taken in late stage of the growing period: (a) seen from the air; (b) seen from the ground; (c) A similar Bronze-Age burial of the same kind during excavation (photos: M. Gojda and M. Trefný). 


\subsection{UAV Data, Acquisition and Processing}

The UAV platform used in this study is a modified quadrocopter DJI Phantom 4 (Figure 2a). Modifications consist of a mounted multispectral camera (Figure $2 b$ ) and extra landing gears to protect the sensor. The device has been painted by black color that does not reflect sunlight to avoid a sun gleam on the ground.

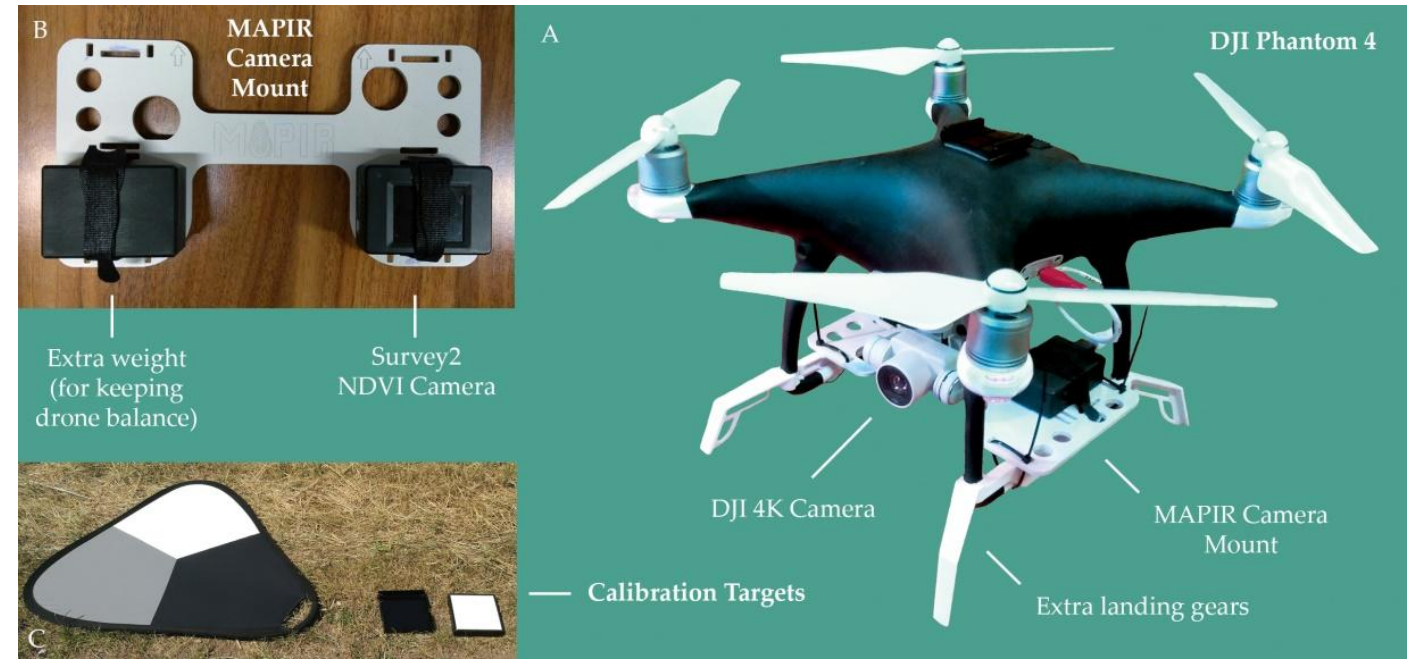

Figure 2. UAV platform: (a) modified quadrocopter DJI Phantom 4; (b) Camera mount with Survey2 NDVI Camera; (c) Calibration targets.

The data acquisition was performed by two sensors at the same time - the original DJI $4 \mathrm{~K}$ camera recording a video in RGB and the Survey2 NDVI camera (Red + NIR, MAPIR [18]) recording images as red and near-infrared bands ( 660 and $850 \mathrm{~nm}$ ). The UAV system was controlled by an autopilot system (the Android application Litchi) which provided autonomous navigation based on the track (waypoints) programmed before the mission. The track was set at a height $30 \mathrm{~m}$ above the ground, the speed was $3 \mathrm{~km} / \mathrm{h}$ and the distances between track lines were defined as $18.6 \mathrm{~m}$ to achieve a $60 \%$ side overlap.

The data acquisition was conducted in June 2017 and the RGB and the Survey2 (Red + NIR) cameras were mounted on the UAV allowing simultaneous data acquiring. The calibration target with white, grey and black patches was placed on the ground in a flight direction to ensure to be a part of the final image mosaics (Figure 2c). The captured datasets consists of RGB video files (MOV) with $4096 \times 2160$ px resolution and Red + NIR images taken every second of the flight with $4608 \times$ 3456 px resolution as RAW + JPEG.

The pre-processing workflow differs for RGB and Red + NIR data (Figure 3). The video files in RGB were splitted to JPEG images in interval of $1 \mathrm{~s}$. We have developed a python script that was used to add the actual data acquisition time to EXIF files of extracted JPEG images. The UAV records a flight track by GPS sensor which was necessary for an assignment of flight coordinates to the JPEG images. This step was performed by the GeoSetter software. The JPEG files of Red + NIR data were located in the same way. The RAW images obtaining all spectral data were united with the located JPEG images to TIFF format by the QGIS plugin provided by the MAPIR (the Survey2 camera producer).The prepared images from the both cameras were processed in the Agisoft PhotoScan Pro software (Figure 3). We have followed the software workflow to get a 3D model and orthomozaic which means-aligning photos, building dense cloud, building DEM and building orthomozaic. The whole process was controlled and manually modified to achieve the best results. 


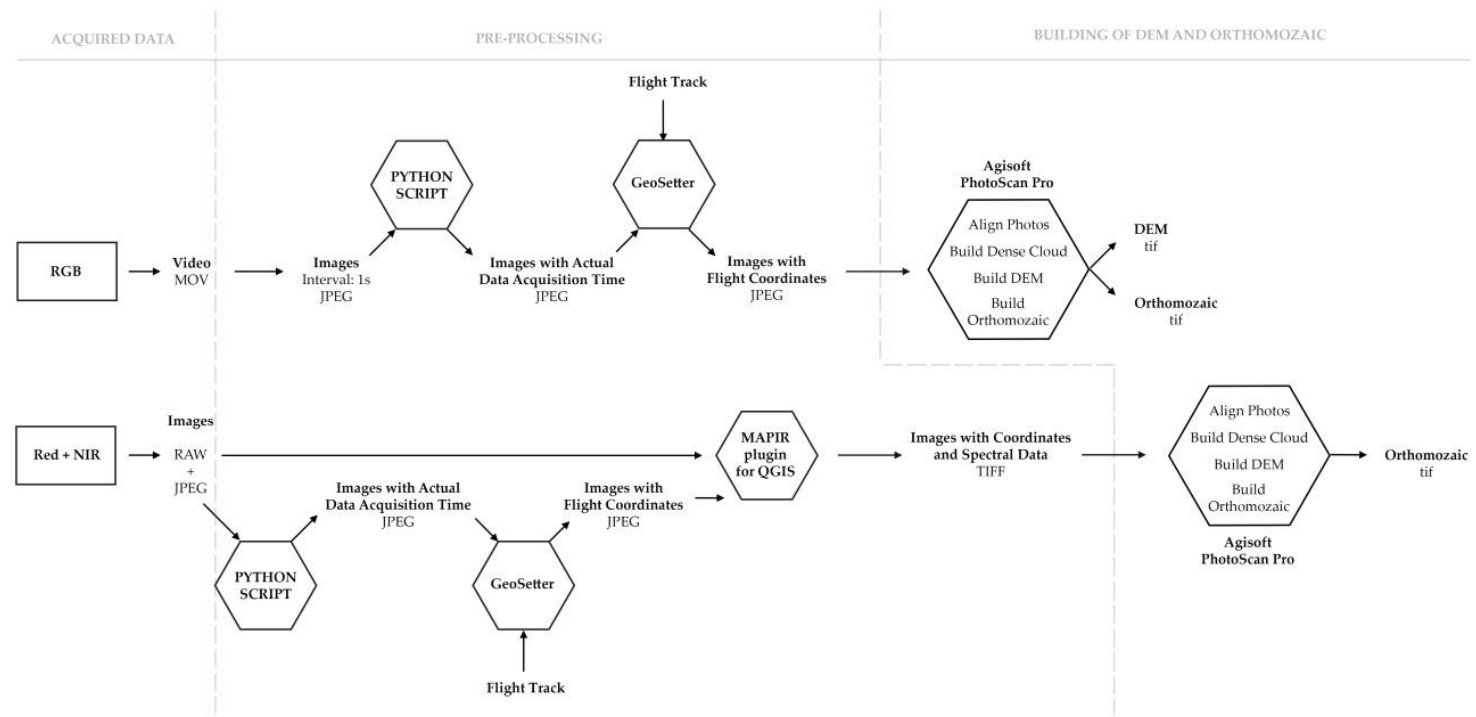

Figure 3. Processing workflow.

\subsection{Red + NIR Data Analyses}

The Red + NIR data were transformed to the reflectance employing the empirical line method [19] using the laboratory-measured reflectance of the light and dark patches of the calibration target (Figure 2c). After that it was possible to build linear calibration equations to convert at-sensor radiance to estimated surface reflectance. Red + NIR reflectance was used to:

- $\quad$ Derive Vegetation Indexes (VI): Normalized Differential Vegetation Index (NDVI) and Simple Ratio Index.

- To employ Decorrelation Stretch (DS) technique to enhance the color differences in Red + NIR data.

The spatial filtering was employed to both the VI and the DS data sets. To enhance image texture Lee filter [20] was used, this filter smooths noise using the multiplicative speckle model, on the other side it also uses local statistics to effectively preserve edge features.

\section{Results and Discussion}

Two Černouček burial ditched enclosures -one rectangular $(12.5 \times 12.5 \mathrm{~m}$, marked II on Figure 4), and one circular (11 $\mathrm{m}$ in diameter, Figure 1, marked I on Figure 4) enclosures near Černouček were scanned by DJI and Survey2 cameras placed at UAV in order to find out whether some other objects of prehistoric origin hidden under the ground-and not evidenced yet during annually repeated visual observations from low flying aircraft - can be detected through Red + NIR data.

The data taken over the Černouček site were processed to one digital elevation model (RGB) with spatial resolution $2.41 \mathrm{~cm} / \mathrm{px}$ and to two orthomozaics (RGB and Red + NIR) with resolution 1.2 $\mathrm{cm} / \mathrm{px}$, respectively $0.99 \mathrm{~cm} / \mathrm{px}$. Remote sensing analyses such as NDVI, Simple Ratio Index and DS were employed to the Red + NIR data.

The results displayed the two ditched enclosures (I and II in Figure 4) discovered in the past and several new objects including two small enclosures (circles with solid lines, Figure 4), possible ditches, with centrally placed points inside them. Some other features (circles with dotted line, Figure 4) may represent single pits of variable function (burial/storage/refuse), but their non-archaeological origin (of at least some of them) is possible as well: without ground truthing by means of geophysical survey or test/sample excavation it is difficult to definitely interpret their age and origin. Anyway, the linear arrangement of the dots indicates their man-made origin. 

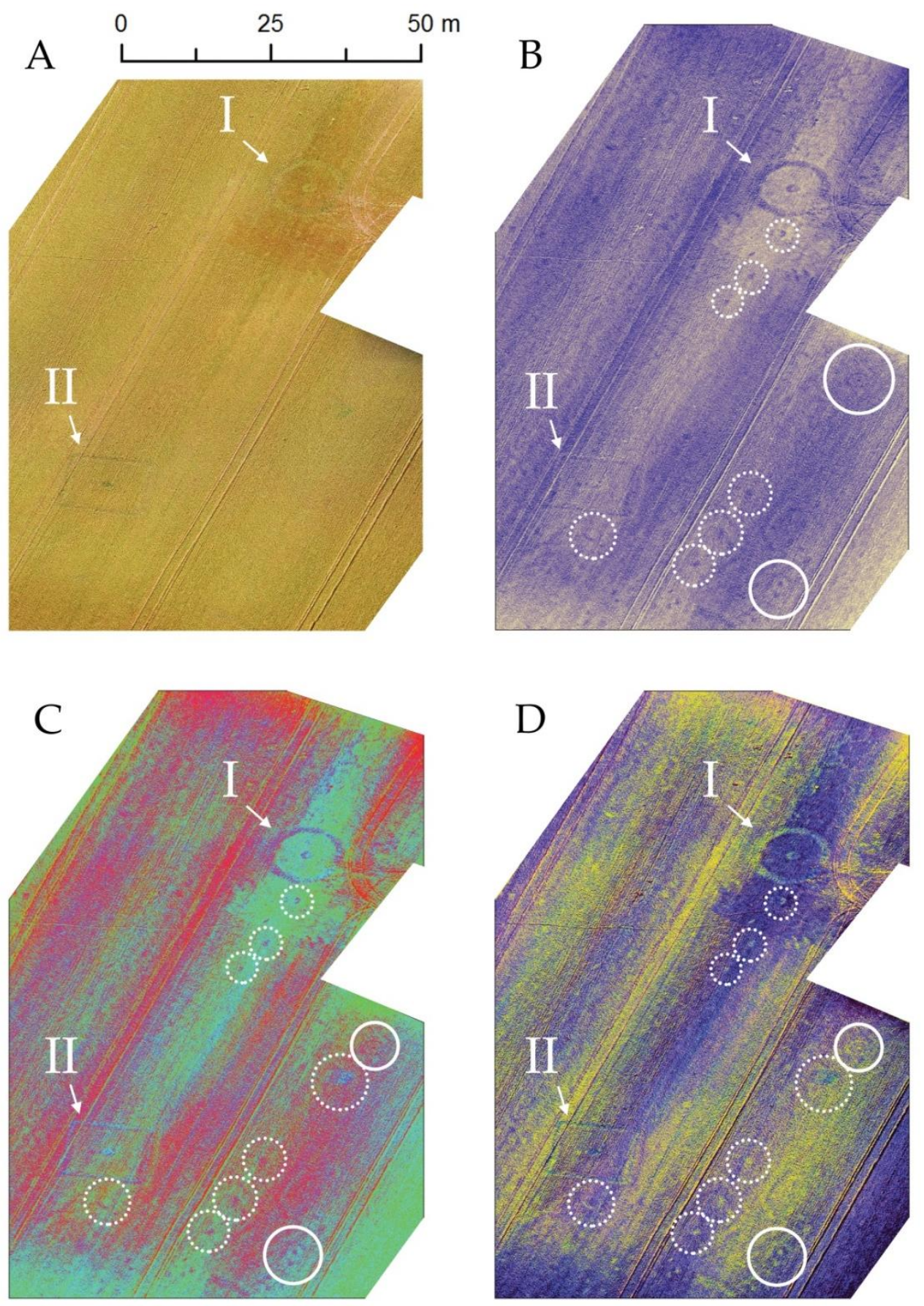

Figure 4. (a) RGB Orthomozaic, Two Černouček burial ditched enclosures-one circular (11 $\mathrm{m}$ in diameter, marked I) and one rectangular $(12.5 \times 12.5 \mathrm{~m}$, marked II). Data Analyses Results-the vegetation anomalies, represented as higher and more dense vegetation, are detectable using Red + NIR processed data and can be identified as these anomalies show regular or structured spatial patterns: (b) vegetation indexes (VI, Normalized Differential Vegetation Index (NDVI), Simple Ratio Index) and the NIR band displayed as RGB; (c) Minimum Noise Fraction (MNF) transformation employed to the DS and VI data; (d) Minimum Noise Fraction (MNF) transformed data (see the c) with enhanced texture using the Lee filter.

\section{Conclusions}

In this study, we examined the usage of remote sensing techniques (such as UAV) in archaeology. The processed data acquired by the UAV-based RGB and Red + NIR cameras over the Černouček burial objects achieved high spatial resolution $(0.99-2.41 \mathrm{~cm} / \mathrm{px})$ and allowed to apply 
remote sensing analyses that discovered already known prehistoric features, as well as a few objects which have not been recorded by conventional aerial reconnaissance.

Future studies should repeat these methods in different seasons to see how different conditions and vegetation affect results. We are also planning to use and compare these data with data recorded by multispectral sensor-Parrot Sequoia. As the project is at the beginning we are going to apply more field work techniques and analyses to discover the origin of new detected features.

Author Contributions: Lucie Koucka recorded the data by UAV, figured out the processing method and prepared a draft version of the manuscript. Veronika Kopackova designed the study, made remote sensing analyses and added her contribution to the manuscript. Katerina Farova processed the data, and Martin Gojda provided an archaeological background, wrote a part of the manuscript and interpreted discovered objects.

Acknowledgments: This study is a part of the project of Czech Geological Survey that is focused on testing of the UAV DJI Phantom 4 for scientific purposes. Project number: 322600.

Conflicts of Interest: The authors declare no conflict of interest.

\section{Abbreviations}

The following abbreviations are used in this manuscript:

$\begin{array}{ll}\text { DEM } & \text { Digital Elevation Model } \\ \text { DS } & \text { Decorrelation Stretch } \\ \text { NDVI } & \text { Normalized Differential Vegetation Index } \\ \text { NIR } & \text { Near-Infrared } \\ \text { UAV } & \text { Unmanned Aerial Vehicle } \\ \text { VI } & \text { Vegetation Index }\end{array}$

\section{References}

1. Agapiou, A.; Lysandrou, V.; Lasaponara, R.; Masini, N.; Hadjimitsis, D. Study of the Variations of Archaeological Marks at Neolithic Site of Lucera, Italy Using High-Resolution Multispectral Datasets. Remote Sens. 2016, 8, 723, doi:10.3390/rs8090723.

2. Comer, D.C.; Harrower, M.J. Mapping Archaeological Landscapes from Space, 1 st ed.; Springer: New York, NY, USA, 2013.

3. Gojda, M.; John, J. Dálkový archeologický průzkum starého sídelního území Čech: Konfrontace výsledků letecké prospekce a analýzy družicových dat-Remote sensing and the study of lowland ancient landscapes in Bohemia: Comparison of the potential of aerial reconnaissance and high-resolution satellite data. Archeol. Rozhl. 2009, 61, 467-492.

4. Lasaponara, R.; Masini, N. Satellite Remote Sensing: A New Tool for Archaeology, 1 st ed.; Springer: Dordrecht, The Netherlands, 2012.

5. Verhoeven, G. Near-Infrared Aerial Crop Mark Archaeology: From its Historical Use to Current Digital Implementations. J. Archaeol. Method Theory 2012, 19, 132-160, doi:10.1007/s10816-011-9104-5.

6. Verhoeven, G.; Sevara, C. Trying to Break New Ground in Aerial Archaeology. Remote Sens. 2016, 8, 918, doi:10.3390/rs8110918.

7. Wilgocka, A.; Raczkowski, W.; Ruciński, D. Romantic versus scientific perspective: The ruins of Radlin palace in Wielkopolska region in the light of remote sensing techniques. In Proceedings of the Third International Conference on Remote Sensing and Geoinformation of the Environment, Paphos, Cyprus, 1619 March 2015, doi:10.1117/12.2195594.

8. Everaerts, J. The use of unmanned aerial vehicles (UAVs) for remote sensing and mapping. Int. Arch. Photogramm. Remote Sens. Spat. Inf. Sci. 2008, 37, 1187-1192.

9. Remondino, F.; Barazzetti, L.; Nex, F.; Scaioni, M.; Sarazzi, D. UAV photogrammetry for mapping and 3d modeling-current status and future perspectives. Int. Arch. Photogramm. Remote Sens. Spat. Inf. Sci. 2011, 38, C22.

10. Hunt, E.R.; Hively, W.D.; Fujikawa, S.J.; Linden, D.S.; Daughtry, C.S.T.; McCarty, G.W. Acquisition of NIRgreen-blue digital photographs from unmanned aircraft for crop monitoring. Remote Sens. 2010, 2, 290-305, doi:10.3390/rs2010290. 
11. Candiago, S.; Remondino, F.; De Giglio, M.; Dubbini, M.; Gattelli, M. Evaluating Multispectral Images and Vegetation Indices for Precision Farming Applications from UAV Images. Remote Sens. 2015, 7, 4026-4047, doi:10.3390/rs70404026.

12. Moriarty, C. Deploying multispectral remote sensing for Multitemporal Analysis of Archaeological Crop Stress at Ravenshall, Fife. Unpublished work, The University of Edinburgh, Edinburgh, UK, 2017.

13. Themistocleous, K.; Agapiou, A.; Cuca, B.; Hadjimitsis, D.G. Unmanned aerial systems and spectroscopy for remote sensing applications in archaeology. In Proceddings of the 36th International Symposium on Remote Sensing of Environment, The International Archives of the Photogrammetry, Remote Sensing and Spatial Information Sciences XL-7/W3, Berlin, Germany, 11-15 May 2015; pp. 1419-1423, doi:10.5194/isprsarchives-XL-7-W3-1419-2015.

14. Gojda, M.; Trefný, M. Archeologie krajiny pod Řípem-Archaeology in the Landscape around the Hill of Říp, 1st ed.; University of West Bohemia: Pilsen, Czech Republic, 2011.

15. Trefný, M.; Dobeš, M. Pohřebiště ze střední až mladší doby bronzové ve Straškově, okres Litoměřice. Archeol. Středních Čechách 2008, 12, 205-243.

16. Gojda, M. Ancient Landscape, Settlement Dynamics and Non-Destructive Archaeology, 1st ed.; Academia: Prague, Czech Republic, 2004.

17. Gojda, M.; Hejcman, M. Cropmarks in main field crops enable the identification of wide spectrum of buried features on archaeological sites in Central Europe. J. Archaeol. Sci. 2012, 39, 1655-1664, doi:10.1016/j.jas.2012.01.023. Available online: www.sciencedirect.com/science/article/pii/S0305440312000350 (accessed on 5 February 2018).

18. MAPIR: Survey2 Camera-NDVI Red + NIR. Available online: www.mapir.camera/collections/survey2/products/survey2-camera-ndvi-red-nir (accessed on 5 February 2018).

19. Smith, G.M.; Milton, E.J. The use of the empirical line method to calibrate remotely sensed data to reflectance. Int. J. Remote Sens. 1999, 20, 2653-2662, doi:10.1080/014311699211994.

20. Xiao, J.; Li, J.; Moody, A. A detail-preserving and flexible adaptive filter for speckle suppression in SAR imagery. Int. J. Remote Sens. 2003, 24, 2451-2465, doi:10.1080/01431160210154885. 